\title{
INCONGRUÊNCIAS DO ARTIGO 45-A DA LEI N 8.212, DE 1991
}

\author{
Lázaro Alves Martins Júnior \\ Doutorando em Direito Constitucional na Faculdade \\ Autônoma de Direito de São Paulo - Fadisp, e Juiz de \\ Direito da 11 - Vara da Comarca de Ceres, Estado de Goiás. \\ mag.lamjunior@tjgo.jus.br
}

\section{Recebido em: 21/7/2017}

Aceito em: 27/7/2017

\section{Resumo}

A entrada em vigor do artigo 45-A da Lei o 8.212, de 1991, com o texto imposto pela Lei Complementar no 128, de 2008, cria no ordenamento jurídico brasileiro a indenização, sem existência de dano, por dívida que se existiu foi atingida pela decadência, nova idiossincrasia que busca arrecadar mais tributos por meio de normas injustas e com o mote falacioso de insolvência do sistema previdenciário que escamoteia a histórica inação dos administradores públicos sufragada pela leniência dos órgãos de fiscalização.

\section{Palavras-chave}

Previdenciário. Decadência. Indenização. Dano. Bis in idem.

\section{INCONGRUITIES OF ARTICLE 45-A OF LAW 8.212, 1991}

\section{Abstract}

The entry into vigor of Article 45-A of Law no 8.212 of 1991, with the text imposed by Complementary Law no. 128, 2008, creates the Brazilian legal system compensation without existence of damages of debt that existed was affected by decadence, new idiosyncrasy that seeks to raise more taxes through unfair and misleading to the motto of the insolvency of pension system that sidesteps inaction history of public officials suffraged by the leniency of the supervisory states organisms.

\section{Keywords}

Pension. Decadence. Compensation. Damages. Bis in idem.

\section{Sumário}

1 Introdução. 20 Artigo № 45-A da Lei o 8212, de 1991. 3 Decadência. Extinção do Direito. 4 Indenização. Dano. 5 Inexistência de Dano. 6 Quebra de Isonomia. "Bis in Idem". A Incorreta Leitura Sob Prisma Angusto da Lei. 7 Conclusão. 8 Referências. 


\section{INTRODUÇÃO}

O sistema previdenciário brasileiro é rotineiramente acusado de deficitário e um, senão o maior, viláo das contas públicas. Este mote, não verdadeiro, foi tão disseminado que a populaçáo passou a crer nele de uma forma quase que lisérgica, sem questionamentos.

A partir do assentamento desta premissa falaciosa, todos os malabarismos jurídicos perpetrados pelo Estado são aceitos em busca da não falência do sistema previdenciário, um engodo que seculariza.

A Lei Complementar no 128, de 19 de dezembro de 2008, incluiu na Lei $n^{\circ} 8.212$, de 24 de julho de 1991, o artigo no 45-A, no qual, iconoclasticamente o Estado conseguiu subverter todos os cânones básicos que envolvem os institutos da indenização e da decadência; passamos a ter no ordenamento jurídico brasileiro a indenização sem dano, e mais, direito material exigível, embora atingido pela caducidade.

Nesse diapasão, este texto busca demonstrar que a interpretação do referido artigo dentro da concepção substancialista de onde se extrai a norma a partir do texto legal, deve receber o influxo de temperamentos e validar a máxima de tratar os iguais como assim sendo, e os desiguais na medida das assimetrias vislumbradas.

\section{ARTIGO N 45-A DA LEI No 8.212, DE 1991}

O artigo no 45-A da Lei no 8.212 , de 1991, inserido e em vigor por força da Lei Complementar no 128 , de 2008, recebeu o seguinte texto:

Art. 45-A. O contribuinte individual que pretenda contar como tempo de contribuição, para fins de obtenção de benefício no Regime Geral de Previdência Social ou de contagem recíproca do tempo de contribuição, período de atividade remunerada alcançada pela decadência deverá indenizar o INSS.

$\$ 1^{\circ}$. O valor da indenização a que se refere o caput deste artigo e o $\$ 1^{\circ}$ do art. 55 da Lei no 8.213, de 24 de julho de 1991, corresponderá a 20\% (vinte por cento): 
I - da média aritmética simples dos maiores salários-de-contribuição, reajustados, correspondentes a $80 \%$ (oitenta por cento) de todo o período contributivo decorrido desde a competência julho de 1994; ou

II - da remuneração sobre a qual incidem as contribuiçóes para o regime próprio de previdência social a que estiver filiado o interessado, no caso de indenização para fins da contagem recíproca de que tratam os arts. 94 a 99 da Lei no 8.213, de 24 de julho de 1991, observados o limite máximo previsto no art. 28 e o disposto em regulamento.

Extreme de dúvidas a conclusão após a leitura acurada do texto legal, que por uma via transversa o direito que foi ceifado em sua exigibilidade pela decadência é repristinado com um vigor extraordinário, transmutado por mera ficção jurídica em direito a uma indenização.

\section{DECADÊNCIA. EXTINÇÃO DO DIREITO}

A decadência faz sucumbir de forma definitiva um direito material detido pela pessoa. Operado este fenômeno de matiz temporal com intuito subjacente de instalar segurança jurídica no cenário das relaçóes negociais ou tributárias, não há que se falar em dever de pagamento pelo inadimplente e tampouco em direito de recebimento pelo credor.

Trata-se de instituto vetusto, com utilização frequente e assentada ao longo do tempo na órbita jurídica. Venosa (2011a, p. 574) conceitua a decadência nos seguintes termos:

.... lei pode subordinar o direito, para se tornar efetivo, à condição de ser exercido dentro de certo período de tempo, sob pena de decadência. Se o titular do direito deixar de exercê-lo, deixando transcorrer em branco o prazo, sem tomar a iniciativa, opera-se sua extinção, a caducidade ou decadência, não sendo mais lícito ao titular colocá-lo em atividade.

Destarte, torna-se de curial clareza que o direito material não mais assegurado ao Estado por meio do fisco, volta à tona mediante a inovaçáo legislativa em comento revelando absoluto conflito com todo o ordenamento jurídico nacional. 


\section{INDENIZAÇÃO. DANO}

É cediço no meio jurídico que a responsabilidade civil, em qualquer de suas espécies, exige o ato ilícito comissivo ou omissivo; o dolo ou a culpa, estes eventualmente desnecessários, verbi gratia, em negócios ou fatos jurídicos que envolvam relação de consumo em que foi erigida como aplicável a responsabilidade civil objetiva; o nexo causal que é o liame entre o ato ilícito e o dano; e resta como certo que o elemento dano ou prejuízo obrigatoriamente deve se apresentar para que ecloda o dever de indenização. Existe ligação umbilical e obrigatória entre o elemento dano e a indenização; portanto sem dano, ao menos moral, inexiste a responsabilidade do agente de promover a indenização.

Em todos os campos do Direito, seja consumerista, civil, trabalhista, etc., não se vê doutrina que assente a obrigação de indenização sem a presença do dano.

Zelmo Denari (2004, p. 182), em obra doutrinária elaborada pelos engenheiros do Código de Defesa do Consumidor promove o seguinte escol alinhado a nossa premissa:

2 RESPONSABILIDADE E SEUS ELEMENTOS - Ao dispor, no art. 12, que o fabricante, produtor, construtor e o importador respondem pela reparaçáo dos danos causados aos consumidores, independentemente da existência de culpa, o Código acolheu, desenganadamente, os postulados da responsabilidade objetiva, pois desconsidera, no plano probatório, quaisquer investigaçóes relacionadas com a conduta do fornecedor. A aboliçáo do elemento subjetivo da culpa na aferição da responsabilidade não significa a exclusão dos demais pressupostos já comentados, a saber: eventus damni, defeito do produto, bem como relação de causalidade entre ambos.

Nery Júnior (2005, p. 267), em diapasão harmônico ao do autor já citado afirma que:

8. Natureza da responsabilidade civil. A responsabilidade civil é a consequência da imputaçấo civil do dano à pessoa que lhe deu causa ou que responda pela indenização correspondente, nos termos da lei ou do contrato. A indenizaçáo é devida pelo responsável por ter natureza compensatória e/ou reparatória do dano causado. 
Diniz (2003, p. 180) na essência, em relação à necessidade da existência do dano para que se obrigue outrem a indenizar, caminha no mesmo sentido:

Ato ilícito. $\mathrm{O}$ ato ilícito é praticado em desacordo com a ordem jurídica, violando direito subjetivo individual. Causa dano patrimonial ou moral a outrem, criando o dever de repará-lo (CC, art. 927). Logo, produz efeito jurídico, só que este não é desejado pelo agente, mas imposto pela lei (RT, 721:106, 720:268, 718:209...).

O clássico civilista Rodrigues (2002, p. 185) traça as mesmas lindes com esta construção textual:

65. Conceito de indenização. Consideraçóes sobre o seu cálculo - Indenizar significa ressarcir o prejuízo, ou seja, tornar indene a vítima, cobrindo todo o dano por ela experimentado. Esta é a obrigação imposta ao autor do ato ilícito em favor da vítima.

Arrematando na seara doutrinária, Baptista apud Venosa (2011b, p. 39) robustece as conclusóes dos demais civilistas:

Dano consiste no prejuízo sofrido pelo agente. Pode ser individual ou coletivo, moral ou material, ou melhor, econômico e não econômico. A noção de dano sempre foi objeto de muita controvérsia. Na noçáo de dano está sempre presente a noção de prejuízo. Nem sempre a transgressão de uma norma ocasiona dano. Somente haverá possibilidade de indenizaçáo, como regra, se o ato ilícito ocasionar dano. Cuida-se, portanto, do dano injusto, aplicação do princípio pelo qual a ninguém é dado prejudicar outrem (neminem laedere) (BAPTISTA, 2003, p. 47).

A jurisprudência pátria não destoa deste entendimento, conforme podemos aferir em decisão do Superior Tribunal de Justiça:

ADMINISTRATIVO E PROCESSUAL CIVIL. AGRAVO REGIMENTAL NO AGRAVO REGIMENTAL NO AGRAVO EM RECURSO ESPECIAL. APRECIAÇÃO DE VIOLAÇÃO A DISPOSITIVOS CONSTITUCIONAIS. INVIABILIDADE, NA VIA DE RECURSO ESPECIAL. RESPONSABILIDADE CIVIL DO ESTADO. PERSECUÇÃO PENAL. EXCESSO QUANTO À BUSCA E APREENSÃO DE DOCUMENTOS, SEM ORDEM JUDICIAL. ACÓRDÃO RECORRIDO QUE, À LUZ DAS PROVAS DOS 
AUTOS, CONCEDEU, AO AUTOR, APENAS A INDENIZAÇÃO POR DANOS MORAIS. SÚMULA 7/STJ. MAJORAÇÃO DOS VALORES FIXADOS PARA INDENIZAÇÃO POR DANOS MORAIS E A TÍTULO DE HONORÁRIOS ADVOCATÍCIOS. REEXAME DE PROVAS. SÚMULA 7/STJ. AGRAVO REGIMENTAL IMPROVIDO. I. A análise de suposta ofensa a dispositivos constitucionais compete exclusivamente ao Supremo Tribunal Federal, nos termos do art. 102, inciso III, da Constituiçáo da República, sendo defeso o seu exame, no âmbito do Recurso Especial, ainda que para fins de prequestionamento, conforme pacífica jurisprudência do STJ. II. O Tribunal de origem, ao decidir a controvérsia, concluiu pela ausência de comprovação dos danos materiais, bem como pela manutenção do valor da indenização arbitrado pela sentença, a título de danos morais, ao argumento de que, "de todos os fatos afirmados como fundamento à pretensão, o único que realmente destoa da regularidade investigatória diz respeito à invasáo do escritório sem ordem judicial, cuja violação ensejou o reconhecimento do dano moral e sua indenização". Concluiu, ainda, que, "ainda que os fatos narrados, além da invasão sem ordem judicial, ensejassem (e não ensejam) reparação, com toda a certeza jamais modificariam o valor fixado a título de dano moral para os patamares pretendidos, por evidente desproporção e desatendimento do escopo do instituto, de modo que fica mantido o valor fixado, sendo descabida a majoração, assim como em relação à verba honorária, valores esses que, além disso, não foram impugnados pela Fazenda Estadual”. Quanto ao dano material, entendeu que "não se pode tratá-lo por dano hipotético, de modo que deve ser comprovado a menos o an debeatur para que se configure o dever de indenizar a tal titulo. E nada foi comprovado nesse sentido". III. A jurisprudência do STJ "admite, em caráter excepcional, que o montante arbitrado a título de danos morais seja alterado, caso se mostre irrisório ou exorbitante, em clara afronta aos princípios da razoabilidade e da proporcionalidade. No caso, o agravante não foi capaz de demonstrar que o valor da indenização seria excessivo, não logrando, portanto, afastar o óbice da Súmula 7/STJ” (STJ, AgRg no AREsp 417.115/PE, Rel. ministro SÉRGIO KUKINA, PRIMEIRA TURMA, DJe de 18/02/2014). No mesmo sentido: STJ, AgRg no REsp 1.496.167/AC, Rel. ministro MAURO CAMPBELL MARQUES, SEGUNDA TURMA, DJe de 19/12/2014. IV. Na hipótese, o Tribunal de origem, em face das peculiaridades fáticas do caso, manteve o valor da indenização por danos morais, fixados, pela sentença, em 15 (quinze) salários mínimos, observando os princípios da proporcionalidade e da razoabilidade, náo se mostrando ele irrisório, ante o quadro 
fático delineado no acórdão de origem. Conclusão em contrário encontra óbice na Súmula 7/STJ. V. No caso, os honorários advocatícios foram mantidos, pelo Tribunal de origem, em 15\% sobre o valor da condenação principal, atento às circunstâncias a que se refere o art. $20, \$ 4^{\circ}$, do CPC, sendo certo que o autor não restou vitorioso, em todas as pretensões deduzidas na inicial. Tal contexto não autoriza a modificação pretendida, de maneira que não há como acolher a pretensão do recorrente, para a majoração dos honorários, em face do óbice da Súmula 7/STJ. Nesse sentido: STJ, AgRg no AREsp 472.319/RS, Rel. ministro MAURO CAMPBELL MARQUES, SEGUNDA TURMA, DJe de 02/05/2014. VI. Agravo Regimental improvido. (AgRg no AgRg no AREsp 520.161/SP, Rel. ministra ASSUSETE MAGALHÂES, SEGUNDA TURMA, julgado em 10/11/2015, DJe 20/11/2015) (Destaquei).

Sintetizando, inexiste previsão legal ou raciocínio lógico desenvolvido ao longo de todo o caminho trilhado na construção da "ciência" jurídica que admita uma indenização por um dano hipotético, em que não se tenha abatido efetivamente a órbita patrimonial material ou moral de alguém.

\section{INEXISTÊNCIA DE DANO}

O Estado brasileiro, como mencionado alhures, é tomado pela sensação de que um dos mais graves problemas nacionais é o previdenciário. Não obstante, inexiste demonstração exata de onde provém este déficit. Nada é divulgado de forma clara, objetiva e pública. Apontam bilhões de desequilíbrio orçamentário, e só.

O que se afigura, sem qualquer sombra de dúvidas, é que há uma histórica irresponsabilidade dos administradores do Executivo somada à leniência do Legislativo e Judiciário.

Existe um assombroso silêncio com relação à existência ou não de fundos de previdência dos entes federativos. Afinal, a contribuiçáo descontada da remuneraçáo do servidor é efetivamente depositada em um fundo que é gerido com o fito de garantir a futura aposentadoria ou estas quantias são destinadas para outras atividades estatais? Os repasses dos empregadores, empresários e os pagamentos dos contribuintes são destinados exatamente e exclusivamente para os cofres do Instituto Nacional do Seguro Social - INSS - ou também são alvo de outros empenhos? 
Inexplicavelmente, os fundos do Banco do Brasil, a Previ e o dos Correios, criados para gestáo da previdência privada destes servidores, são bilionários, investem em diversas áreas e são alvo de investidas espúrias dos governantes diante das ingentes quantias financeiras que movimentam; no mesmo diapasão as instituiçôes financeiras investem com maciças campanhas buscando açambarcar o mercado e investidores em fundos previdenciários privados.

Descortina-se um paradoxo: por que os banqueiros se interessariam por um negócio deficitário e por qual motivo os fundos previdenciários citados são tão frutíferos se a realidade é ostensivamente negativa como reverbera a administraçáo pública?

Este suposto paradoxo é desfeito quando mais bem entendida a conduta dos gestores públicos, como se discorre adiante.

O conceituado tributarista Machado (2003, p. 384-385), há tempos alerta acerca deste flagrante descompasso entre a arrecadação, destinação e gestão, e o motivo subjacente que, novamente, hodiernamente, se repete nas articulaçóes políticas do Executivo federal atual buscando reviver a chamada CPMF:

Näo obstante inconstitucionais as contribuiçôes criadas pela Uniäo com suposto fundamento no art. 195, I, da Constituiçäo Federal, para integrarem o orçamento do Tesouro Nacional, continuam elas a serem arrecadadas pelo Tesouro Nacional, em flagrante violação ao disposto no art. 165, \$5º, combinado com o art. 194, parágrafo único, inciso VII da Constituiçāo Federal, que determinam tenha a seguridade social orçamento próprio e gestão descentralizada.

Não pode prevalecer, como sustentam alguns, por ignorância ou má-fé, o princípio da unidade orçamentária. Esse princípio não pode sobrepor-se à Constituição Federal, que estabeleceu de forma diferente exatamente para superar tal principio, que ficou restrito às contas do Tesouro e das autarquias comuns. Não se aplica à seguridade social, que se tornou uma autarquia de nivel constitucional por força dos supracitados dispositivos.

O exame dos balanços gerais da União revela que as contribuiçôes de previdência, cujo total representava, em 1989, apenas $34 \%$ da receita tributária, passou a oscilar entre 110\% e 121\% nos anos de 1990 até 1994. Em 1995 a arrecadação dessas contribuiçôes correspondeu a mais de $148 \%$ da receita tributária. Em outras palavras, as contribuiçöes de previdência corresponderam, em 1995, a quase vez e meia tudo quanto a Uniáo arrecadou com todos os seus tributos. 
Como se pode acreditar que a seguridade social esteja falida?

É mais razoável acreditar-se que as receitas desta, arrecadadas pelo Tesouro Nacional, sob as vistas complacentes do Supremo Tribunal Federal, estejam sendo desviadas para outras finalidades.

E, o que é ainda mais grave, que as autoridades do governo utilizam-se do argumento de que a seguridade social, especialmente a área de saúde pública, está carente de recursos, para obter o apoio na criação de novos tributos, como aconteceu com a CPMF, porque a sensibilidade dos contribuintes näo lhes permite recusar recursos para esse segmento do Estado. Segmento que desgraçadamente continuará carente, em virtude de inevitáveis desvios, prestando-se, apenas, como argumento para seguidos aumentos de carga tributária.

Basta uma análise perfunctória das inúmeras fontes de receita destinadas pela legislaçáo para o sistema previdenciário para termos a certeza de que os números fornecidos à imprensa e à população não são verdadeiros.

Martins Júnior (2011, p. 170-172) apud Sérgio Pinto Martins, sistematiza as fontes variadas de arrecadação do Estado-Previdência ligadas ao Regime Geral da Previdência Social. Náo se pode cometer o oblívio de não alertar sob a pulsante e atual tentativa de retomada da CPMF, que até então jazia em câmara sepulcral:

De espantosa clarividência a certeza de que as fontes de recursos para a seguridade social é rica e diversificada, não podendo ser olvidado que a União é a exclusiva responsável pela cobertura de insuficiências de caixa na seguridade social.

A quantidade de contribuiçóes e suas fontes exigiriam um longo e extenso texto, por este motivo, transcrevo uma compilação do trabalho de Sérgio Pinto Martins enumerando as diversas exaçóes com este fulcro, constando as contribuiçóes do trabalhador, outras espécies de contribuintes, empresa e receitas diversas:

- Contribuição do Trabalhador - art. 195, II CF/88. (salário, abonos, comissóes e percentagens, gratificações permanentes, $13^{\circ}$ salário, férias e ganhos habituais)

- Contribuinte individual (Lei 8.212 com redação Lei 9876);

- Empregador Rural Pessoa Física e Segurado Especial;

- Aposentado;

- Contribuição da empresa (art. 195, I, CF/88) - Folha de Salários, retenção prestação de serviços (Lei 9.711/98 nova redação ao art. 31 da Lei 8.212/91), autônomo que remunera autônomo (advogado que paga advogado), Custeio de 
Acidente de Trabalho, Empregador Doméstico; Contribuição do Produtor Rural e do Segurado Especial, Contribuiçāo do Empregador Rural Pessoa Jurídica, Contribuição da Cooperativa Rural, Contribuiçóes de Terceiros (Art. 240 CF/88 - destinadas a entidades privadas de serviço social e formação profissional - Sesi, Senac, Sesc, Senai...), Contribuiçāo ao Senar (Serviço Nacional de Aprendizagem Rural - Lei 8.315/91 - CNA - Confederação Nacional de Agricultura), SEST, Senat (Serviço Social do Transporte e Serviço Nacional de Aprendizagem do Transporte - Lei 8.706/93), Sebrae (Lei 8.029/90), Sescoop (Medida Provisória 2.168), Incra (Lei 2.613/55), Salário-Educação (lei 4.440/64), Contribuição sobre o Faturamento (Confins - Contribuição para financiamento da seguridade social - destinado à União e fiscalizado pela Receita Federal e não pelo INSS - LC 70/91); PIS/Pasep; CSSL - Contribuição Social Sobre o Lucro; Simples).

- Contribuição sobre a receita de concursos de prognósticos;

- CPMF (extinta);

- Outras Receitas (multas, atualização monetária e os juros moratórios); remuneração recebida pelos serviços de arrecadação, fiscalização e cobrança prestados a terceiros (Sesi, Sesc, Senai, etc.).; prestação de outros serviços e fornecimento ou arrendamento de bens - Dataprev - serviço de processamento de dados; receitas patrimoniais - aluguéis - industriais e financeiras; doaçōes, legados, subvenções e outras receitas eventuais; $50 \%$ dos valores obtidos e aplicados decorrentes de tráfico de entorpecentes e drogas (parágrafo único do artigo 243 CF/88); $40 \%$ do resultado dos leilóes dos bens apreendidos pelo Departamento da Receita Federal; outras receitas previstas em legislação específica; $50 \%$ do prêmio do seguro DPVAT (Direito da Seguridade Social (Sergio Pinto Martins, 2002, p. 139-231) (grifei).

Em verdade, o que se materializa no âmbito da gestão pública é o desvio dos valores descontados a título previdenciário do servidor público que não são destinados aos fundos respectivos; no Regime Geral de Previdência Social, o desvio consubstancia nos recolhimentos que sáo feitos diretamente ao Tesouro Nacional, e não aos cofres do INSS.

Como pode alcançar um superavit um instituto que náo recebe recursos?

$\mathrm{O}$ que aparentemente ocorre é regularmente a cobertura pelo Tesouro dos benefícios pagos aos servidores públicos aposentados, que deveriam provir do respectivo fundo náo criado e gerido responsavelmente, a mesma conduta se reproduzindo no pagamento dos proventos da área privada. 
Degenerada em sua essência, esta transferência de recursos é tida como se consubstanciasse um desfalque no erário, entretanto, eventualmente, pode ser inferior ao que seria, por lei, creditado aos cofres do INSS pelo contribuinte se observados os comandos legais e as regras comezinhas da boa gestão administrativa e financeira.

Dessarte, não há como se falar em prejuízo ou dano a ser indenizado com espeque no artigo 45-A da Lei no 8.212, de 1991. O sistema previdenciário nacional é um emaranhado de desmandos que carece de atuação segura, firme, dos órgãos de fiscalização e aplicação severa da Lei pelo Judiciário para ceifar o falacioso prejuízo, com a correta aplicação dos recursos arrecadados.

Os números de per si provam isso, esclarecem e realçam o motivo da atração da iniciativa privada nesta seara. Um trabalhador que percebe um salário mínimo mensal equivalente, em 2016, a $\mathrm{R} \$ 880,00$ (oitocentos e oitenta reais), contribuindo com $8 \%$ (oito por cento) deste valor, empregará $\mathrm{R} \$ 70,40$ (setenta reais e quarenta centavos) mensais, e ao final de 35 anos, estas quantias, mesmo que rasamente aplicadas na caderneta de poupança, que é um dos menos rentáveis investimentos do mercado, com média inferior a $1 \%$ (um por cento) ao mês (por volta de $0,60 \%$ no período), gerará um montante de $\mathrm{R} \$ 133.001,58$ (cento e trinta e três mil, um real e cinquenta e oito centavos), que proporcionará uma renda sobre o capital equivalente a $\mathrm{R} \$ 798,01$ (setecentos e noventa e oito reais e um centavo) para o pagamento do benefício. Mesmo com o desfalque de menos de R \$100,00 (cem reais mensais) do capital com os pagamentos mensais dos proventos, esta quantia aliada aos juros contínuos é suficiente para o pagamento do benefício por aproximadamente 35 anos futuros.

Não obstante, as explicaçóes se complicam ainda mais para o gestor previdenciário quando agregamos ao montante os $12 \%$ (doze por cento) de contribuição do empregador, o que representa um valor total mensal recolhido de $\mathrm{R} \$ 176,00$ (cento e setenta e seis reais) mensais, gerando um capital de $\mathrm{R} \$ 332.503,95$ (trezentos e trinta e dois mil quinhentos e três reais e noventa e cinco centavos), que possibilita, com os mesmos parcos rendimentos da caderneta de poupança, o pagamento de um benefício no patamar de $\mathrm{R} \$ 1.995,02$ (um mil novecentos e noventa e cinco reais e dois centavos).

Sintetizando, os recolhimentos do empregador e do empregado no sistema celetista geram, em conjunto, ao final de 35 anos, um capital de $\mathrm{R} \$ 465.505,53$ (quatrocentos e sessenta e cinco mil quinhentos e cinco reais e cinquenta e três 
centavos), possibilitando um rendimento mensal de $\mathrm{R} \$ 2.793,03$ (dois mil setecentos e noventa e três reais e três centavos), sobejamente suficiente para pagar os proventos e ainda abastecer o erário ao final.

Não se pode olvidar que o contribuinte facultativo, o profissional liberal, recolhe $20 \%$ (vinte por cento) do salário de contribuição, o que resulta em um montante equivalente ao anteriormente dissecado.

Em suma, o Regime Geral da Previdência, devidamente administrado, gera um capital capaz de suportar valor superior em três vezes o benefício pago.

$\mathrm{Na}$ mesma esteira o servidor público contribui com, em regra, no mínimo 11\% (onze por cento) de sua remuneração a título previdenciário, existindo Estados em que o recolhimento alcança 13,25\%, como no caso de Goiás.

$\mathrm{Na}$ seara da previdência estatal no caso de uma remuneração de $\mathrm{R} \$$ 10.0000,00 (dez mil reais mensais), os valores acumulados e aplicados na alquebrada caderneta de poupança com os mesmos índices acima expostos, geram após 35 anos a quantia de $\mathrm{R} \$ 2.078 .149,72$ (dois milhóes, setenta e oito mil, cento e quarenta e nove reais e setenta e dois centavos), possibilitando ao ente federativo que tenha caucionado e aplicado devidamente estas contribuiçóes, o pagamento de proventos de até $\mathrm{R} \$ 12.468,90$ (doze mil, quatrocentos e sessenta e oito reais e noventa centavos), isso sem qualquer contrapartida da administraçáo e ainda preservando a esta o capital formado após o encerramento do pagamento dos proventos com o falecimento do servidor e inexistência de dependentes.

Não se pode confundir a previdência com a assistência social e a saúde. Aquela tem caráter contributivo e com a Emenda Constitucional no 41, de 2003, expurgou as ficçóes e privilégios indevidos. As demais obrigaçóes devem ser bancadas também pelos tributos em geral, não podendo haver o deslocamento dos recursos para fabricar um déficit justificando a contínua burla e sanha arrecadatória do Estado.

Outros vetores de pagamentos com via única provinda do erário, sem a contrapartida contributiva, como os benefícios aos segurados especiais, também devem receber novo tratamento, algo parecido com o que se aplicou aos empregados domésticos nacionais, formalizando a relação e, mesmo que recebendo em menor patamar, expurgando o grande número de fraudes, uma vez que a realidade brasileira não é mais agrária e é inexplicável, a partir de justificativas morais e legais, constatar 
que existem mais açóes judiciais previdenciárias em trâmite, arguindo a condição de rurícolas e pugnando pelo benefício, que a própria população rural aferida pelo Instituto Brasileiro de Geografia e Estatística - IBGE.

Não se comete o oblívio de não atentar esse estudo sobre a existência de dois sistemas de previdência mais difundidos: a capitalizada, onde cada trabalhador gera o montante individualizado que lhe proporcionará o benefício nos termos acima explanados; e, em segundo lugar, contraposto àquele, o sistema de repartição simples ou orçamentária, supostamente adotado hodiernamente pelo Brasil, onde uma geração arca com os benefícios da anterior e assim sucessivamente pelas geraçóes vindouras, se submetendo, todas, às variáveis sociais.

Não obstante, nunca foi claramente exposto à sociedade os números financeiros desta operação de repartição simples e onde as possíveis portentosas sobras iniciais foram despendidas, e qual a razão de não se promover a transição de sistemas quando se verificou, pelo discurso governista e a reiterada conduta reformista do mesmo no setor previdenciário ao longo dos anos, a completa ausência de sustentabilidade no modelo de repartição simples, agravando-se o risco de que a "contribuição compulsória" encubra, mais uma comezinha malversação dos recursos do erário, onde despesas a título de assistência social ou correlatas são imputadas aos proventos pagos.

\section{QUEBRA DE ISONOMIA. "BIS IN IDEM". A INCORRETA LEITURA SOB PRISMA ANGUSTO DA LEI}

O legislador pautou-se na inovação legal apenas na intenção de constituir mais uma fonte de arrecadação da suposta combalida Previdência Social brasileira, e por isso não se empenhou em observar que o tratamento linear é obtuso, consistindo a leitura sob um prisma angusto, com antolhos, da Lei no 8.212, de 1991 em seu artigo 45-A, um tremendo disparate, um novo golpe contra o contribuinte.

O contribuinte que está inserido no sistema contributivo, seja no Regime Geral de Previdência Social ou em regime Estatutário após a Emenda Constitucional no 41, de 2003, não alcançará nenhum benefício superior por recolher as contribuiçóes atrasadas calculadas sobre o salário mínimo vigente à época, pois será 
este valor que participará do cômputo geral que comporá o seu benefício. Não há prejuízo ao sistema, pois o percentual de contribuição advém de cálculo atuarial e, como visto anteriormente, é sobejamente suficiente para este fito.

Somente podemos aventar um ataque ao sistema previdenciário e que deve ser repelido, mas que não se pode mensurar se consubstanciaria de fato um prejuízo diante da tessitura orçamentária que provocou um verdadeiro amálgama nas fontes dos recursos levados ao erário ao longo das décadas, os casos de servidores públicos que foram investidos no cargo em período anterior à Emenda Constitucional $\mathrm{n}^{\mathrm{o}}$ 41, ou que prestaram serviços anteriores a este lapso temporal, e que queiram ver reconhecido este tempo de serviço, recolhendo sobre o salário- mínimo da época, mas repercutindo para sua aposentadoria com proventos integrais, mesmo com resgate de contribuiçóes pretéritas feito com supedâneo em valores sensivelmente inferiores; neste ponto andou bem a Lei por estarmos diante das impropriedades que a Emenda Constitucional no 41, de 2003 buscou coibir.

Vale ressaltar que a contribuição que a Lei estipulou no artigo 45-A travestida de indenizaçáo, pelo período atrasado e atingido pela caducidade, tendo como parâmetro outras remuneraçôes, não representa "indenização", mas, efetivamente, contribuição previdenciária que constitui o direito a uma contraprestação no benefício.

No caso do servidor ou empregado sujeito às regras já amoldadas à Emenda Constitucional acima em comento, portanto sob a égide do regime contributivo que repercute no benefício, exigir deste que "indenize" o INSS com base em outros períodos salariais é indevido e promove a violação ao princípio do "non bis in idem”, uma vez que o contribuinte contribuirá duas vezes sobre uma mesma remuneração, embora deslocada da realidade econômica que viveu, bem como o da isonomia, o que éfacilmente demonstrável.

Um contribuinte que deixou de contribuir por três anos, percebia um salário mínimo em sua relação empregatícia anterior e reingressou no mercado de trabalho ganhando novamente o mínimo legal, recolherá sobre o mínimo da época passada. Seu cálculo de proventos será, sempre, sobre o salário mínimo, salvo se em nova relação empregatícia alcance outro patamar remuneratório.

Outro contribuinte que percebia remuneração equivalente a três salários mínimos, tornou-se profissional liberal e teve renda igual ou equivalente a um salário mínimo, posteriormente ingressou no serviço público já sob a vigência da 
Emenda Constitucional no 41, de 2003, terá de "indenizar" o INSS com base em sua nova remuneraçáo, que já foi alvo da incidência de descontos previdenciários, forçando reconhecer a configuração do inaceitável "bis in idem", uma vez que a mesma remuneração será tributada duas vezes, deslocando o INSS o contribuinte da sua realidade econômica vivida no período, que pode ser provada por várias formas, p.e., a declaração de imposto de renda, documento que mesmo homologado pela Receita Federal é ignorado solenemente pelo Instituto, demonstrando um verdadeiro desprezo pelo órgão de seu ente controlador, a União, o que ao final é um contrassenso e uma negativa de legitimidade do próprio Estado.

Assim sendo, o contribuinte se vê compelido a pagar um valor exorbitante sem qualquer garantia de retorno equivalente ou aproximado em várias hipóteses, v.g., se este contribuinte vier a ter alteração em sua relação empregatícia e contar com um menor nível de remuneração futura.

Em verdade, essa indenização, verdadeira contribuição travestida com nome de outro instituto, in casu, indenização, sem a presença de seus elementos essenciais, acaba desestimulando o recolhimento, o que apenas prejudica o sistema previdenciário, pois o contribuinte inserido no regime contributivo sob a tutela da Emenda Constitucional no 41 terá seus benefícios calculados pelos recolhimentos efetivos promovidos. Se menores, menor o benefício, com a mesma relação de causa e efeito em caso de pagamentos superiores.

\section{CONCLUSÃO}

O legislador brasileiro, em parte induzido a erro pelo etéreo e alardeado déficit previdenciário histórico, em verdade um escamotear das verdadeiras causas, quais sejam, a incompetência e corrupção do administrador; e em outra parte conluiado com os rumos governamentais no sentido de aumentar a arrecadação, nunca suficiente, criaram no Direito brasileiro a indenizaçâo sem dano, ou por dano hipotético, como resultado da fantasiosa versão criada para iludir a população e congressistas menos atentos. 
Escapa a muitos que a Matemática é uma ciência exata e o sistema foi criado solidamente sob a regência da mesma e mesmo sob a égide de um inicial sistema previdenciário de repartição simples ou orçamentário, as finanças previdenciárias nunca se mostraram transparentes e carecem, de tempos em tempos, de reformas, tornando questionável o motivo da não transição para o sistema previdenciário capitalizador, escoimando destas contas os gastos a título de assistência social.

No contexto do estudo aqui apresentado, muitos contribuintes são prejudicados. O sistema previdenciário certamente deixa de arrecadar verbas que o robusteceriam e com uma leitura mais atenta da Lei fica inequívoco que apenas aqueles que foram inseridos no serviço público de forma anterior à Emenda Constitucional $n^{\circ} 41$, de 2003, é que devem estar sujeitos ao recolhimento das parcelas em atraso referentes a períodos laborados com base em sua remuneração atual, não prejudicando sua aposentadoria, todavia não lhe garantindo subterfúgios para uma aposentadoria precoce, bancada pelo Estado, ou seja, por todos, sem a devida contraprestação do trabalhador a partir do robustecimento do elemento contributivo em sede magna.

O sistema previdenciário, na teoria, é totalmente autossustentável e só não se solidifica nestes termos pela atuação material espúria, amadora e irresponsável dos gestores públicos, acostumados a manter o poder com base em populismos e sem a mínima atenção aos verdadeiros males que enfraquecem a estrutura estatal e o próprio Estado Democrático de Direito, que se vê em risco diante do panorama que se desenha, cada vez mais assustador e desalentador.

Múltiplas causas afligem o Estado brasileiro e sua população, entretanto, o sistema previdenciário não é o problema na forma e em dimensão que lhe atribuem. Em verdade torna-se supedâneo para incremento de práticas tributárias gananciosas que, ao final, nunca são suficientes em virtude do fito do gestor público ser outro, inexistindo personagens públicos dispostos a discutir o sistema previdenciário a partir de uma perspectiva séria e que trace lindes claras e objetivas para o funcionamento contributivo e capitalizado.

As obrigaçóes estatais de cunho assistencialista e com a saúde, típicas de um Estado Social moderno, que admite o capitalismo mas deve extrair dele benesses, não se confundem com o benefício previdenciário de caráter contributivo, em que a relação deve ser comutativa, diferida no tempo e pautada em administração revestida de seriedade, o que lamentavelmente se mostra ausente de forma pujante nesta área. 
A transição dos sistemas previdenciários da espécie repartição simples para capitalizada é, aparentemente, uma obrigação quando se adota um sistema contributivo, não podendo esta fórmula suportar despesas estatais de outra ordem, vez que estas tornam necessário que se passe a exigir dos contribuintes mais do que por eles é devido, o que promove o corroer perene e sistemático do modelo orçamentário ou de repartição simples, sempre fadado a volatilidade, diferente do capitalizado que é expressão matemática.

\section{REFERÊNCIAS}

DINIZ, Maria Helena. Código Civil anotado. 9. ed. rev. e atual. de acordo com o novo Código Civil (Lei n. 10.406, de 10-1-2002). São Paulo: Saraiva, 2003.

GRINOVER, Ada Pellegrini et al. Código brasileiro de defesa do consumidor: comentado pelos autores do anteprojeto. 8. ed. Rio de Janeiro: Forense Universitária, 2004.

MACHADO, Hugo de Brito. Curso de Direito Tributário. 22. ed. rev., atual. e ampl. Sáo Paulo: Malheiros, 2003.

MARTINS JÚNIOR, Lázaro Alves. A derrocada do Estado Social a partir da degeneração do sistema de Seguridade Social. 2011. Disponível em: <https://jus.com.br/artigos/17921/a-derrocada-do-estado-social-a-partir-da-degeneracao-do-sistema-de-seguridade-social>. Acesso em: 18 fev. 2016.

NERY JÚNIOR, Nelson. Código Civil comentado e legislação extravagante: atualizado até 15 de junho de 2005. 3. ed. rev., atual. e ampl. da segunda edição do Código Civil anotado. São Paulo: Ed. Revista dos Tribunais, 2005.

PAULA, Gil César Costa de (Org.). Justiça global: Estado, cidadania e políticas públicas no mundo atual. Goiânia: Ed. Vieira, 2011.

RODRIGUES, Silvio. 1917 - Direito civil. Responsabilidade civil. Sáo Paulo: Saraiva, 2002. V. 4.

TAVARES, André Ramos. A constituição é um documento valorativo? Revista Brasileira de Direito Constitucional, São Paulo, n. 9, p. 337-348, jan./jun. 2007.

VENOSA, Sílvio de Salvo. Direito Civil: parte geral. 11. ed. São Paulo: Atlas, 2011 aa. V. 1. . Direito Civil: responsabilidade civil. 11. ed. São Paulo: Atlas, 2011bb. V. 4. 